\title{
Review
}

\section{Structure of the PRC2 complex and application to drug discovery}

\author{
Yi SHI ${ }^{1, *}$, Xiao-xi WANG ${ }^{1}$, You-wen ZHUANG ${ }^{1}$, Yi JIANG $^{1}$, Karsten MELCHER ${ }^{2}, \mathrm{H}_{\text {Eric }} \mathrm{XU}^{1,2, *}$ \\ ${ }^{1}$ Key Laboratory of Receptor Research, VARI-SIMM Center, Center for Structure and Function of Drug Targets, Shanghai Institute of \\ Materia Medica, Chinese Academy of Sciences, Shanghai 201203, China; ${ }^{2}$ Laboratory of Structural Sciences, Van Andel Research \\ Institute, Grand Rapids, MI 49503, USA
}

\begin{abstract}
The polycomb repressive complexes 2 (PRC2) complex catalyzes tri-methylation of histone H3 lysine 27 (H3K27), a repressive chromatin marker associated with gene silencing. Overexpression and mutations of PRC2 are found in a wide variety of cancers, making the catalytic activity of PRC2 an important target of cancer therapy. This review highlights recent structural breakthroughs of the human PRC2 complex bound to the H3K27 peptide and a small molecule inhibitor, which provide critically needed insight into PRC2-targeted drug discovery.
\end{abstract}

Keywords: PRC2; histone methyltransferase; H3K27me3; nucleosome; structure; drug discovery

Acta Pharmacologica Sinica (2017) 38: 963-976; doi: 10.1038/aps.2017.7; published online 17 Apr 2017

\section{Introduction}

Epigenetic regulation, including DNA methylation and demethylation, histone modification, chromatin remodeling, incorporation of histone variants and chromatin modulation by non-coding RNAs, plays a key role in modulating the chromatin state and gene expression without altering the DNA sequence $^{[1-5]}$. Polycomb group proteins (PcGs) are important epigenetic regulators that form chromatin-modifying complexes, whose composition may be cell-context-dependent. In mammals, two major PcG complexes, namely Polycomb repressive complexes 1 (PRC1) and 2 (PRC2), have been identified $^{[1,6,7]}$.

PRC1 catalyzes the monoubiquitylation of histone H2A Lys $119^{[1,8]}$. Once thought of as a unique complex, it is now clear that human PRC1 exists as a modular subset of complexes with distinct functions and gene targets ${ }^{[8]}$. All PRC1 complexes contain a common core - the RING-type E3 ubiquitin ligase composed of Ring1B (also known as RNF2) or Ring1A, and Bmi1 (also known as PCGF4) or one of six Polycomb group RING finger (PCGF) subunits, as well as additional subunits that define canonical PRC1 (CBX and PHC subunits) and noncanonical PRC1 (RYBP/YAP2 $)^{[8,9]}$. The subunit com-

\footnotetext{
${ }^{*}$ To whom correspondence should be addressed.

E-mail eric.xu@simm.ac.cn (H Eric XU); shiyi@simm.ac.cn (Yi SHI)

Received 2016-12-19 Accepted 2017-01-10
}

position affects both PRC1 recruitment to target genes and the catalytic activity of the complex ${ }^{[8,9]}$. PRC2 catalyzes the methylation of histone H3 lysine 27 (H3K27) through its EZH2 subunit, a modification thought to mediate transcriptional silencing through chromatin compaction ${ }^{[1,10]}$. Monoubiquitylation of histone H2A Lys 119 (H2AK119ub) by PRC1 recruits PRC2 ${ }^{[1]}$, while the PRC1 component PC (known as CBX in mammals) binds specifically to the product of PRC2 catalysis, H3K27me3. This results in a binding feed-forward loop and the spread of both the H2AK119ub and H3K27me3 repressive marks ${ }^{[1]}$. Together, PRC1 and PRC2 silence critical target genes involved in fundamental cellular processes such as cell fate decision, cell differentiation, cell cycle regulation, senescence and cancer ${ }^{[1,6,7,11,12]}$.

Dysregulation of PRC2 is involved in a wide variety of cancers, making the catalytic activity of PRC2 an important target of cancer therapy. Here, we review recent structural breakthroughs of the human PRC2 complex bound to the H3K27 peptide and a small molecule inhibitor, which could serve as a rational basis for drug discovery that targets PRC2.

\section{Polycomb repressive complex 2: subunit composition}

Human PRC2 consists of four core subunits (Enhancer of zeste homolog 2 [EZH2], embryonic ectoderm development [EED], suppressor of zeste 12 [SUZ12], and retinoblastoma suppressor associated protein 46/48 [RbAp46/48]) and several auxiliary subunits including AE (adipocyte enhancer)-binding 
protein 2 [AEBP2], Jumonji/AT-rich interactive domain 2 [JARID2] and polycomb-like [PCL] proteins 1,2 , and $3^{[1]}$. EZH2 is the enzymatic subunit of PRC2. The 751-amino-acid EZH2 protein harbors six domains: a WD-40 binding domain (WDB), domains I-II, two SWI3-ADA2-N-CoR-TFIIIB [SANT] domains, a cysteine-rich CXC domain and the evolutionarily conserved carboxy-terminal $\mathrm{Su}$ (var) 3-9-enhancer of zestetrithorax (SET) methyltransferase domain. However, EZH2 lacks histone methyltransferase (HMTase) activity on its own and requires at least two other PRC2 core subunits, EED and SUZ12, for catalytic activity ${ }^{[1,13,14]}$.

EED both recruits PRC2 to H3K27me3 and stimulates EZH2 H3K27me3 HMTase activity. Four EED isoforms are found in mammals, and these isoforms are thought to form through alternative use of four in-frame translation start sites in the EED mRNA ${ }^{[15]}$. All isoforms appear to be capable of facilitating PRC2-dependent histone methylation both in vivo and in vitro ${ }^{[15]}$. EED folds into a typical WD-repeat/ $\beta$-propeller structure. The WD40 motif is composed of an approximately 40 -amino-acid fold that forms four-stranded antiparallel $\beta$-sheets, with seven copies of the WD-repeat motif forming the seven-bladed $\beta$-propeller structure of $\mathrm{EED}^{[16]}$. A 30-residue peptide of EZH2 (aa39-68) is both necessary and sufficient for its interaction with EED ${ }^{[16]}$. The EED-EZH2(39-68) structure revealed binding of the EZH2 peptide to the bottom of the WD-repeat domain of $\mathrm{EED}^{[16]}$. This interaction is required for the HMTase activity of PRC2 ${ }^{[16]}$. The carboxy-terminal domain of EED specifically binds the N-terminal tail of H3K36me3, which is required for allosteric activation of the HMTase activity of PRC2 ${ }^{[13]}$.

SUZ12 is essential for the integrity of the PRC2 complexes, the stability of EZH2, and hence the HMTase activity of the complex $^{[14,17]}$. It contains a C-terminal Vrn2-Emf2-Fis2-SUZ12 [VEFS] domain, a $\mathrm{C} 2 \mathrm{H} 2$ zinc finger and an extended N-terminal region with sequence blocks that are conserved from plants to humans ${ }^{[18]}$. The C-terminal VEFS domain mediates stable binding to EZH2, which promotes PRC2 assembly ${ }^{[14,19]}$. Beyond simply providing EZH2 contact, the VEFS domain plays an allosteric role in stimulating PRC2 HMTase activity ${ }^{[19]}$. Furthermore, recent findings implicate the SUZ12(VEFS) domain in allosteric inhibition of EZH2 HMTase activity by H3K4me3, a modification that marks transcriptionally active promoters, to inhibit the spread of silenced chromatin into active gene regions ${ }^{[20]}$. Thus, the VEFS domain provides a key surface for EZH2 interaction to activate the PRC2 catalytic site and also mediates regulatory inputs that control enzyme output.

The region spanning residues 79-91 of SUZ12 provides a binding surface for the $\mathrm{RbAp} 46 / 48$ subunit ${ }^{[18,20]}$. Besides its contributions to the core PRC2, there is also evidence that SUZ12 mediates interactions with the PRC2 cofactor JARID2 ${ }^{[18,21]}$. Moreover, SUZ12 is the PRC2 subunit with the strongest affinity for a set of noncoding RNAs (ncRNAs) from the $5^{\prime}$ ends of repressed target genes ${ }^{[18,22]}$.

RbAp46 and RbAp48 (pRB-associated proteins p46 and p48, also known as RBBP7 and RBBP4, respectively) are highly homologous histone chaperones that play key roles in establishing and maintaining chromatin structure ${ }^{[23-25]}$. Although $\mathrm{RbAp} 46 / 48$ proteins are not required for the HMTase activity of EZH2 and do not appear to stimulate it, they have important PRC2-related function ${ }^{[26]}$. RbAp48 binds to histone $\mathrm{H} 3-\mathrm{H} 4$ heterodimers to recruit the PRC2 complex to nucleosomes ${ }^{[24,26]}$. While both RbAp46 and RbAp48 are PRC2 components, it remains unknown whether they have distinct functions in the context of PRC2.

AEBP2 is a zinc-finger protein that was identified as an auxiliary component of the PRC2 complex ${ }^{[1,27]}$. It interacts with EZH2 and SUZ12 to enhance EZH2 enzymatic activity ${ }^{[1,28]}$ and co-localizes with PRC2 at a number of target genes ${ }^{[1,27]}$.

JARID2 is a transcriptional repressor ${ }^{[29]}$ and a member of the Jumonji C (JmjC) and ARID domain protein family of histone demethylases, yet it lacks the key residues necessary for cofactor binding and is devoid of enzymatic activity ${ }^{[1,21,30]}$. The C-terminal half of JARID2 contains the conserved JmjC and JmjN domains, the ARID domain (a potential DNA-binding domain), and a zinc finger, while the N-terminal half contains an allosteric effect domain, a PRC2-binding region and a nucleosome-binding domain ${ }^{[21,30-32]}$. How JARID2 influences PRC2, in mechanistic terms, is less well defined. Methylated JARID2 mimics methylated H3K27me3 to recruit and activate PRC2, and knockdown/loss-of-function experiments revealed a partial mutual dependence on JARID2 and core PRC2 subunits for target binding ${ }^{[21,30-40]}$. JARID2 can bind to long noncoding RNAs (lncRNAs), whose presence stimulates JARID2EZH2 interactions in vitro and JARID2-mediated recruitment of PRC2 to chromatin in vivo ${ }^{[33]}$. JARID2 can also modulate PRC2 histone methyltransferase activity in vitro; however, whether this influence is stimulatory or inhibitory is controversial $^{[21,30-33,37]}$.

PCL proteins were first identified as crucial factors in maintaining normal body segmentation during differentiation in Drosophila ${ }^{[41]}$. Human PCL proteins include PHF1 (hPCL1), MTF2 (hPCL2) and PHF19 (hPCL3). They all contain a Tudor domain and two plant homeodomain (PHD) finger domains, which are conserved across species ${ }^{[42-44]}$. PCLs participate in PRC2 recruitment to their genomic targets for high-level H3K27 trimethylation and Hox gene silencing by an unidentified mechanism. PHF1, but not MTF2, can physically interact with EZH2 via its PHD domain and specifically stimulates EZH2 H3K27me3 activity over H3K27me2 activity ${ }^{[45,46]}$, suggesting that PHF1 not only functions in site-specific PRC2 recruitment but also enhances PRC2's epigenetic repression activity. In addition to its functions in PcGs, PHF1 also plays an important role in double-strand break (DSB) signaling and promoting non-homologous end-joining repair through interaction with $\mathrm{Ku} 70 / \mathrm{Ku} 80^{[47]}$, thus playing a critical role in genome maintenance processes. Another feature worthy of attention is the ability of PHF1 to bind and protect p53 from MDM2-mediated ubiquitination and degradation ${ }^{[48]}$, implicating PHF1 in regulating cell growth arrest and apoptosis. MTF2/PCL2 function has been mainly analyzed in ES cells, where it is a component of biochemically distinct PRC2 com- 

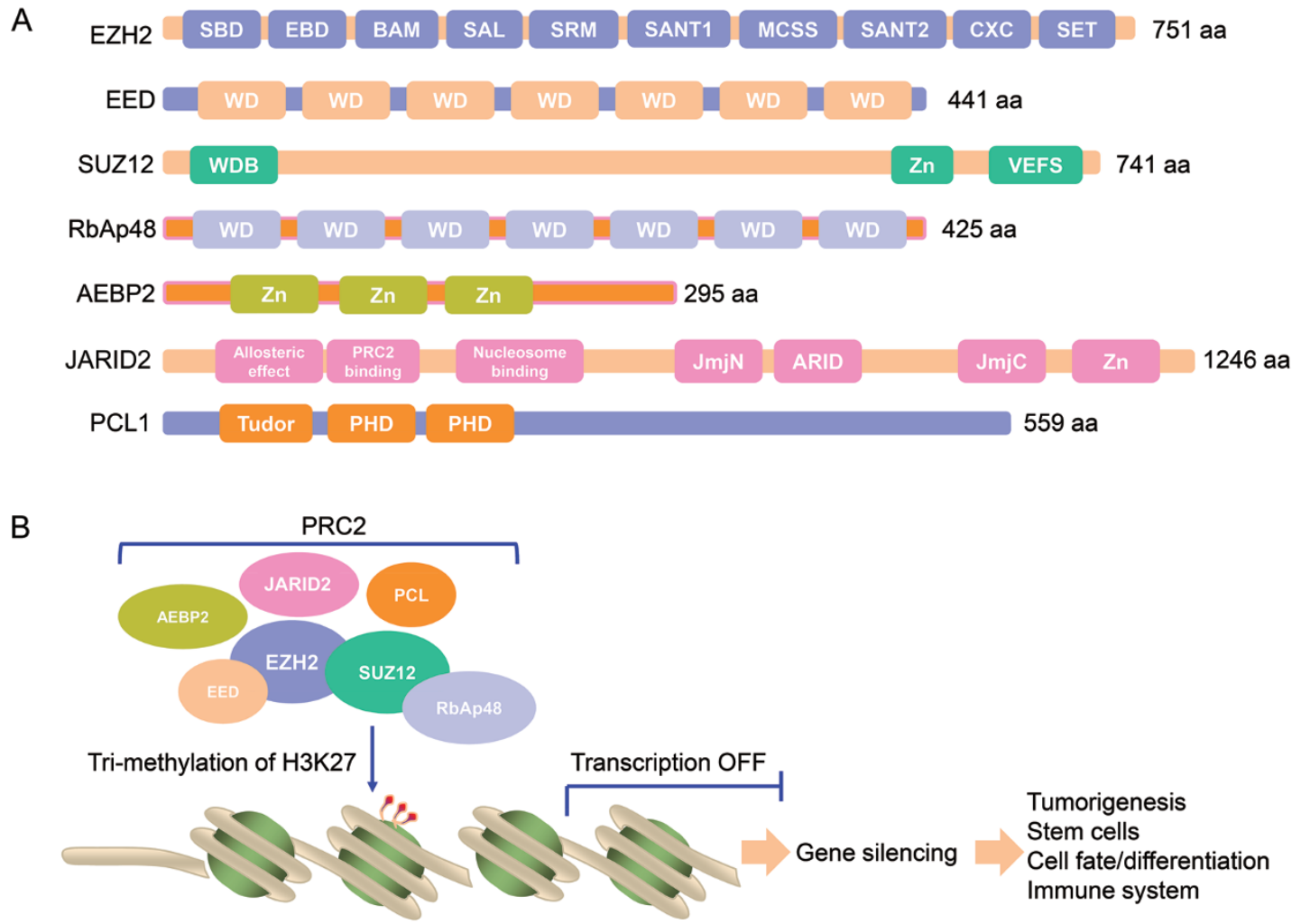

Figure 1. The Polycomb repressive complex PRC2. (A) Domain organization of each subunit in the human PRC2 complex. aa, amino acid; SBD, SANT1-binding domain; EBD, the EED-binding domain; BAM, $\beta$-addition motif; SAL, SET activation loop; SRM, stimulation-responsive motif; MCSS, motif connecting SANT1 and SANT2; SANT, SWI3, ADA2, N-CoR and TFIIIB DNA-binding domain; CXC, cysteine-rich domain; SET, Su(var) 3-9, enhancer of zeste, trithorax domain; WD, WD-40 domain; WDB, WD-40 binding domain; Zn, Zn-finger region; VEFS, conserved among VRN2-EMF2-FIS2-SU(Z)12; JmjN, Jumonji N; ARID, AT-rich interaction domain; JmjC, Jumonji C; PHD, plant homeodomain. (B) Model of the human PRC2 complex. EZH2, EED, SUZ12, and RbA48 are core subunits, while JARID2, PCLs, AEBP2 are auxiliary subunits. PRC2 complex catalyzes tri-methylation of H3K27, leading to compaction of nucleosome and transcription silencing.

plexes that it recruits to HOX genes and other target loci to regulate transcriptional networks during axial development ${ }^{[49,}$ ${ }^{50]}$. Paradoxically, MTF2 is also involved in activating the CDKN2A gene and promotes cellular senescence ${ }^{[49]}$, suggesting that MTF2 might locally suppress the catalytic activity of PRC2. PHF19, the third PCL homologue identified, can form two PHF19 isoforms by alternative splicing, a long form with Tudor and both PHD domains, and a shorter isoform that lacks the C-terminal PHD2. PHF19 binds EZH2 through the Tudor and PHD2 domains ${ }^{[51]}$. PHF19 specifically forms a complex with PRC2 lacking JARID2 in an inter-dependent way ${ }^{[52-54]}$, indicating that it is a potential PRC2-recruting factor. Both PHF19 and PHF1 are able to bind H3K36me3, a well-known marker of active chromatin, through their Tudor domains ${ }^{[53-55]}$. Stunningly, recognition of H3K36me3 is necessary for H3K27me3 deposition and PRC2-colocalization with PHF19 and the specific H3K36 demethylases NO66 and KDM2B ${ }^{[53,54]}$, suggesting that PHF19 targets PRC2 to repress active gene loci. Although much progress has been achieved in unraveling PCL protein functions in PRC2-mediated repression, further research is required to understand when and how PHF1 or PHF19 recognize the H3K36me3 marker and interact with PRC2 to activate its catalytic activity.

Sequences enriched in $\mathrm{CpG}$ islands may play a widespread role in recruiting PRC2 complexes in mammals ${ }^{[1,6,7]}$. PRC2 is recruited indirectly to $\mathrm{CpG}$ islands via PRC1, whose accessory subunit KDM2B specifically recognizes un-methylated CpG islands to recruit PRC1; PRC2 is then recruited through ubiquitylation of histone H2A lysine 119 by RING1B, which is part of the same variant complex that also contains KDM2B ${ }^{[56]}$.

Several recent reports suggest that lncRNAs play an important role in gene silencing and PRC2 recruitment to selective loci ${ }^{[22,33,38,57-67]}$. For instance, PRC2 and H3K27me3 accumulate on the inactive $\mathrm{X}$ chromosome during $\mathrm{X}$ inactivation. Subsequently, it was shown that the key regulator of $\mathrm{X}$ inactivation, the lncRNA Xist, can interact with PRC2 through the PRC2cofactor JARID2 $2^{[3,60]}$. HOTAIR is a lncRNA that recruits PRC2 to the HOXD locus101 ${ }^{[68]}$, whereas the IncRNA Kcnqot1 is involved in imprinting the Kenq1 cluster in a process that requires PRC2 $2^{[69]}$. Moreover, RNA immunoprecipitation techniques have identified several thousand RNAs associated with $\mathrm{PRC}^{[70]}$, but their functional significance remains unclear ${ }^{[1,6,7]}$.

More recently, it has been shown that the pre-mRNA splicing regulator RBFox directly interacts with PRC2, and RBFox2 
inactivation eradicates PRC2 targeting at the majority of bivalent gene promoters leading to transcriptional de-repression ${ }^{[71]}$.

\section{PRC2: biological function}

A central function of PRC2 is to methylate histone H3 on K27. While PRC2 can perform each of the three successive methyl transfers that ultimately yield $\mathrm{H} 3 \mathrm{~K} 27 \mathrm{me} 3^{[7]}$, the tri-methylated product (H3K27me3) is widely viewed as the oppressive chromatin mark that accompanies PcG-mediated silencing ${ }^{[7]}$. While H3K27me2 is broadly distributed, H3K27me3 is more specifically localized at a number of silent genes, including key cell fate regulators ${ }^{[72]}$. Genome-wide mapping studies confirmed that PRC1 and PRC2 co-localize with H3K27me3 at the promoters of $10 \%-15 \%$ of all genes ${ }^{[73,74]}$. These genes include HOX and other developmental and cell fate determination genes, including BMP, WNT, NANOG and SOX ${ }^{[73,74]}$. More recently, PRC2 has been reported to support neuron specification during differentiation through silencing genes responsible for neurodegeneration ${ }^{[75]}$, suggesting an important role for PRC2 in protecting neurons against degeneration.

Based on biochemical and structural data, a PRC2 genesilencing model was proposed in which PRC2 can either act independently or synergistically in response to different chromatin environments: when chromatin domains are targeted for repression, PRC2 is recruited to deposit the repressive H3K27me3 histone mark at nucleosome-associated regions of DNA. Existing H3K27me3 marks are recognized by EED and the stimulation-responsive motif (SRM) of EZH2, which, in cooperation with the SET activation loop (SAL) of EZH2, stabilize the catalytic SET domain of EZH2 to stimulate its methyltransferase activity. However, PRC2 enzymatic activity is inhibited by the active histone marks H3K4me3, H3K36me2, and $\mathrm{H} 3 \mathrm{~K} 36 \mathrm{me} 3$, which in contrast to the unmodified H3 N-terminus are not bound by the VEFS domain of SUZ12 ${ }^{[13,20,28]}$, to ensure that H3K27 trimethylation is limited only to repressed targets and does not spread into active regions.

\section{PRC2 and diseases}

Since 2010, multiple cancer genome-wide studies have revealed that the function of the PRC2 complex and H3K27methylation are widely associated with tumorigenesis $^{[4,5,12,76,77]}$. Several lines of evidence suggest that EZH2 deregulation is an important driver of cancer development and progression and that inactivation of EZH2 may be therapeutically effective in many cancers ${ }^{[4,5,11,12,73,76-89]}$. EZH2 is highly expressed in a wide range of cancer types, including lung, breast, colon, prostate, bladder and pancreatic cancer, as well as sarcomas and lymphomas ${ }^{[4,5,11,12,76,77,80,82,83,85-88]}$. Correspondingly, overexpression of EZH2 often correlates with advanced stages of human cancer progression and poor prog$\operatorname{nosis}^{[4,12,76]}$. Furthermore, somatic mutations and deletions of $\mathrm{EZH} 2$ are found in 22\% of germinal-center diffuse large B-cell lymphomas, $7 \%$ of follicular lymphomas, and $12 \%-23 \%$ of patients with myelodysplastic and myeloproliferative disorders $^{[4,12,76]}$. Similarly, mutations in some epigenetic regulators that are functionally related to EZH2 are also associated with oncogenesis $^{[4,12,76]}$. For example, inactivating mutations of the H3K27 demethylase ubiquitously transcribed tetratricopeptide repeat gene on $X$ chromosome (UTX) recurrently occur in a wide range of malignancies, which may be functionally equivalent to up-regulation of EZH2 methyltransferase activity ${ }^{[88]}$.

PRC2 has also been implicated in various immune functions. For instance, Gunawan et al found that EZH2 is involved in regulating lymphocyte activation through modulation of integrin signaling and adhesion dynamics of neutrophils and dendritic cells ${ }^{[90]}$. Bantug and Hess reported that glycolysis and EZH2 synergistically stimulate $\mathrm{T}$ cell responses against tumors $^{[91]}$, and Zhao et al showed that EZH2 activation stimulates expression of $\mathrm{T}$ cell polyfunctional cytokines and promotes $\mathrm{T}$ cell survival, resulting in enhanced patient survival ${ }^{[92]}$.

\section{PRC2 structure}

Recently, three PRC2 structures were determined: PRC2 of the thermophilic fungus Chaetomium thermophilum (ctPRC2) in a stimulated and basal state ${ }^{[93]}$, human PRC2 in a stimulated state $^{[94]}$ and a human/chameleon (Anolis carolinensis) hybrid PRC2 [Hs/AcPRC2] in complex with a pyridine-based PRC2 inhibitor ${ }^{[95]}$. Although human and fungal PRC2 have low sequence conservation, they share a similar overall structure. The complex crystal structures of all three groups contain EZH2, EED and the VEFS domain of SUZ12. They show that the PRC2 complex has at least two states: a basal state, as shown for PRC2 in the absence of a stimulatory peptide, and a stimulated state in which the same complex contains either the stimulatory H3K27me3 peptide or a stimulatory JARID2K116me3 peptide ${ }^{[93,94]}$. These complexes were further stabilized by binding of SAH cofactor and a substrate-trapping $\mathrm{H} 3 \mathrm{~K} 27 \mathrm{M}$ peptide in the catalytic cleft. H3K27M is an oncogenic mutant histone that binds the EZH2 subunit and inhibits active PRC2 by blocking its methyltransferase activity ${ }^{[94]}$.

Overall, EZH2, EED, and the VEFS domain of SUZ12 (SUZ12(VEFS)) associate intimately to form a compact structure, which is roughly divided into a regulatory module and a catalytic module. The regulatory module is composed of the seven-bladed $\beta$-propeller fold of EED surrounded by a "belt" of the six N-terminal EZH2 domains consisting of the SANT1 domain (in fungal PRC2 SANT1-like domain), the SANT1binding domain (SBD), the EED-binding domain (EBD), the $\beta$-addition motif (BAM), the SET activation loop (SAL) and the stimulation-responsive motif (SRM). The catalytic module is composed of SUZ12(VEFS) and the four C-terminal domains of EZH2, consisting of the motif connecting SANT1 and SANT2 (MCSS), SANT2 (in fungal PRC2 SANT2-like domain), the cysteine-rich domain (CXC), and the Su(var)3-9, enhancer of zeste, trithorax domain (SET). The SET domain is positioned above EED and SUZ12(VEFS) and adjacent to the $\mathrm{SRM}^{[93,94]}$

Within the EZH2 N-terminal fragment, the N-terminal SBD forms a long helix that packs against the C-terminal SANT1 domain to complete an interdomain four-helix bundle. Thus, the first and last of the domains from the EZH2 N-terminal fragment interact to close the ring that EZH2 forms around 
the EED subunit ${ }^{[94]}$. The EBD and BAM domains pack against the bottom and side of the EED. SAL and SRM together link the catalytic SET domain to the H3K27me3-sensing EED to communicate H3K27me3 binding to the catalytic center of the SET domain to stimulate its HMTase activity ${ }^{[94]}$. The MCSS and SANT2 domains provide most of the contacts between EZH2 and the SUZ12(VEFS) domain. SANT2 has a significant proportion of basic residues and a zinc-coordinating site, suggestive of a role in nucleic acid recognition. The HMTase activity of the SET domains requires two adjacent cysteinerich regions, the pre-SET $(\mathrm{CXC})$ and post-SET domains. The pre-SET domain is characterized by two zinc-binding motifs. In the first motif, three $\mathrm{Zn}^{2+}$ ions are coordinated by eight cysteines and one histidine $\left(\mathrm{Zn}_{3} \mathrm{Cys}_{8} \mathrm{His}_{1}\right)$, and in the second motif, another three $\mathrm{Zn}^{2+}$ ions are coordinated by nine cysteines $\left(\mathrm{Zn}_{3} \mathrm{Cys}_{9}\right)$. The motif interacts with SET, SUZ12(VEFS) and the MCSS domain of the catalytic module. The largely disordered post-SET following the SET domain completes, with the SET domain, the lysine access channel and the active site ${ }^{[94]}$. The SET-I region of EZH2 in the human PRC2 complex adopts an anti-clockwise rigid-body rotation relative to its position in isolated structures. Residues 112 to 121 of the SAL pack against the SET-I region to stabilize its conformation in the active complex, and the conserved acidic residues 584-588 of SUZ12 in turn also pack against residues 112-121 of the $\mathrm{SAL}^{[94]}$. This SUZ12 region was previously reported to mediate binding to histone $\mathrm{H} 3$ (31 to 42), resulting in stimulation of PRC2 activity ${ }^{[94]}$.

The EED structure is essentially identical to previously determined crystal structures. Its H3K27me3 recognition site is at the center of the beta-propeller and interacts with the SET domain via SAL and SRM ${ }^{[94]}$.

The N-terminal 29 residues (561-589) of the SUZ12(VEFS) form a random coil that is sandwiched between the EED and EZH2 SET domain, serving as the glue that holds them together ${ }^{[95]}$. Residues 590-685 of SUZ12(VEFS) form a helical bundle with exclusive interactions with different parts of $\mathrm{EZH} 2^{[95]}$. The first four helices interact intimately with the EZH2 MSCC subdomain, and the C-terminal two helices provide an interaction surface for the two $\mathrm{N}$-terminal helices of the EZH2 SANT2 subdomain ${ }^{[94,95]}$ (Figure 2).

Asp652, Gln648, Leu666, Asn668 and Tyr726 of human EZH2 interact with the H3 (22-31) K27M peptide (Figure 3A), while Ala622, Trp624, Ser664, Asn688, His689 and Asp725 form hydrogen bonds with the co-factor SAH (Figure 3C). Therefore, the C-terminal loop is necessary for both SAH and H3K27 peptide binding. The methionine 27 side chain in the H3K27M cancer mutant protein occupies the "lysine" access channel in the active site. Importantly, the interaction with methionine is much stronger than with the wild-type lysine residue and, in the context of full-length PRC2 and H3K27Mcontaining nucleosomes, is thought to inhibit PRC2 activity by almost irreversible binding of the complex to $\mathrm{H} 3 \mathrm{~K} 27 \mathrm{M}^{[94]}$. In the stimulated state of PRC2, Asp362, Arg414 of human EED and Asp140 of human EZH2 respond to the binding of the JARID2K116me3 peptide (Figure 3B), while Glu337, Gln326, Glu39, Arg526, Phe327, Val325 and His326 of fungal EED and Asp329 of fungal EZH2 are involved in H3K27me3 peptide binding (Figure 3D).

More recently, Zhang et al point out that a flexible peptide from ctSUZ12 (aa533-538, LPGRGV) instead of oncogenic H3K27M peptide binds to the active pocket of the ctEZH2 SET catalytic domain in the ctPRC2 structure, leading to misidentification of H3K27M-EZH2 SET interaction ${ }^{[96]}$. Jiao et al replaced the corresponding peptide with an H3K27M peptide sequence in the context of the same EZH2-SUZ12(VEFS) fusion protein and solved the structure of the sequence-modified ctPRC2 in complex with SAM. The renewed structure shows that a methionine but not an arginine residue in the replaced H3K27M sequence from a neighboring asymmetric
A

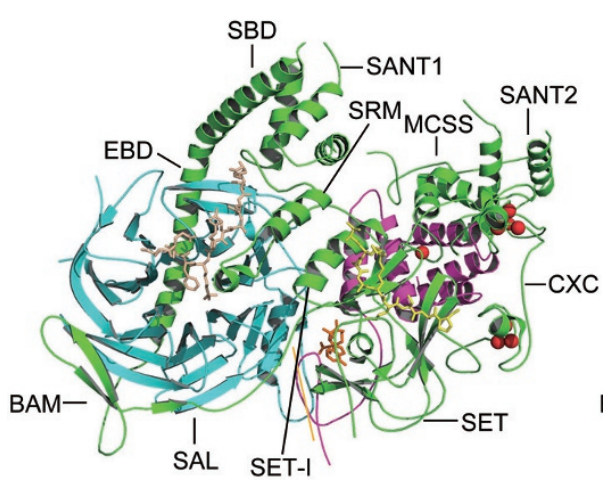

B

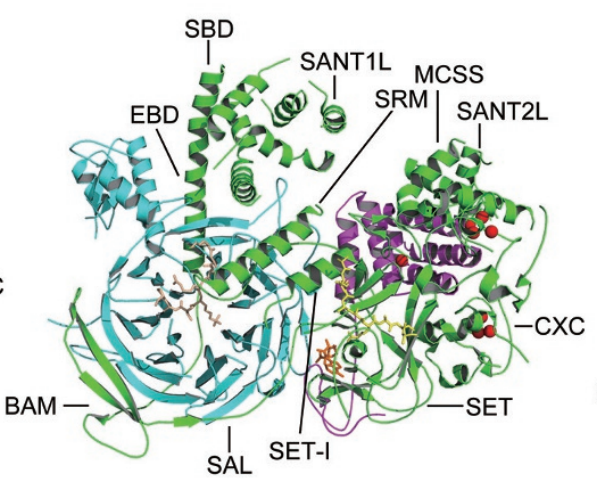

C

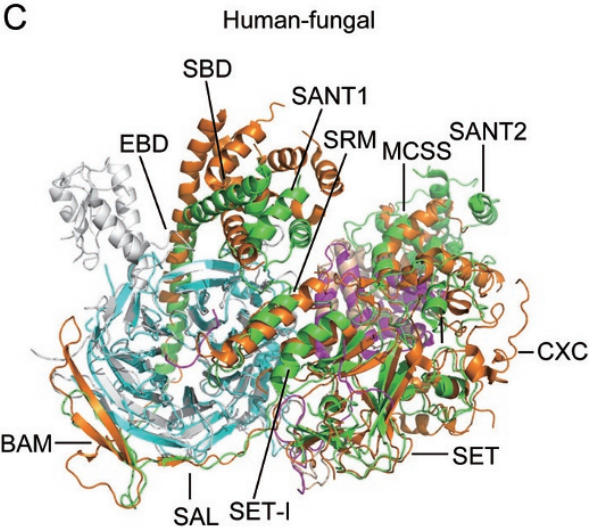

Figure 2. The structure of human PRC2 and fungal PRC2. The structure of human PRC2 (PDB ID: $5 \mathrm{HYN})^{[94]}$ and fungal (C thermophilum) PRC2 (PDB ID: $5 \mathrm{CH} 1)^{[93]}$. (A) The structure of human PRC2. Green: EZH2, cyan: EED, magenta: SUZ12 (VEFS), yellow: H3K27M peptide, orange: SAH, tint: JARID2K116me3 peptide, red: $\mathrm{Zn}^{2+}$. (B) The structure of fungal PRC2. Green: EZH2, cyan: EED, magenta: SUZ12 (VEFS), yellow: H3K27M peptide, orange: SAH, tint: H3K27me3 peptide, red: $\mathrm{Zn}^{2+}$. (C) Alignment of human and fungal PRC2 structure. Structural overlay of human PRC2 (PDB ID: $5 \mathrm{HYN}$ ) and fungal PRC2 (PDB ID: 5CH1). Green: human EZH2, cyan: human EED, magenta: human SUZ12(VEFS), orange: fungal EZH2, gray: fungal EED, wheat: fungal SUZ12 (VEFS). 
A

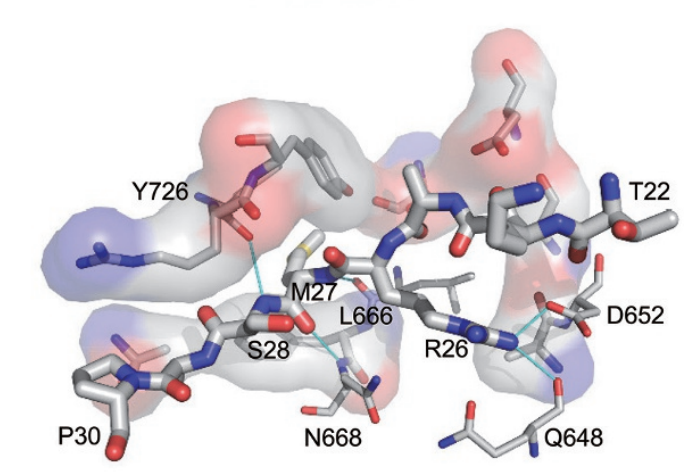

C

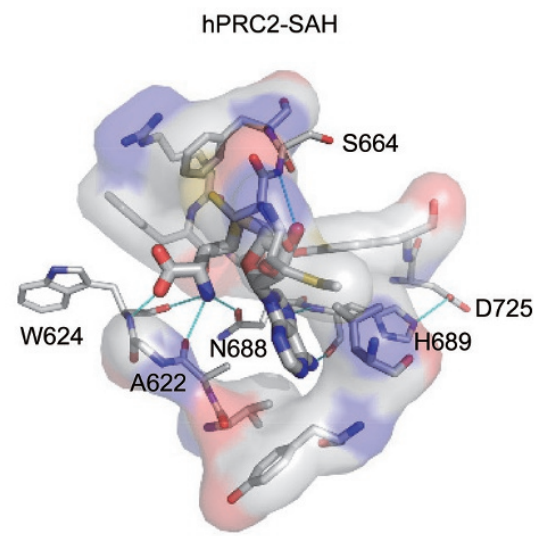

B

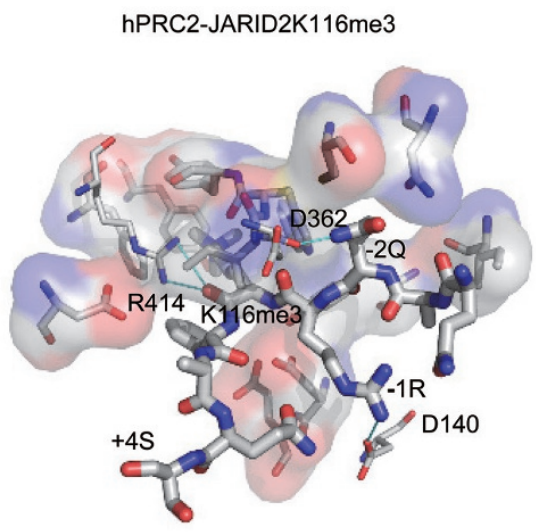

D

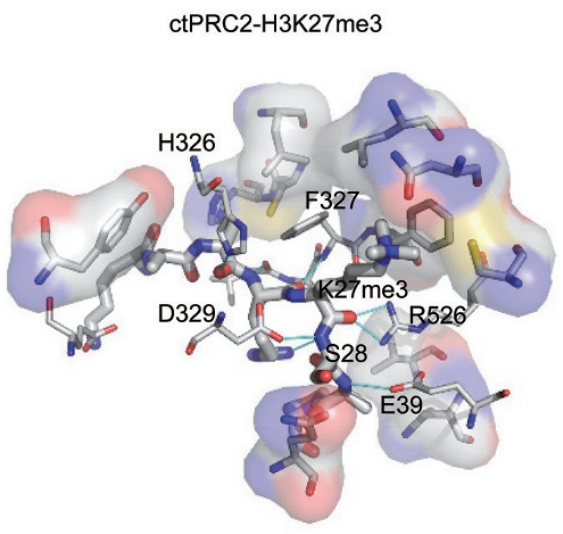

Figure 3. Interaction of PRC2 and substrate. (A) Interaction of human PRC2 with H3K27M peptide. (B) Interaction of human PRC2 with JARID2K116me3 peptide. (C) Interaction of human PRC2 with SAH. (D) Interaction of fungal PRC2 with H3K27me3 peptide. The specific interactions between PRC2 and peptide or SAH are indicated by blue lines. The interactions were analyzed by LigPlus and graphed using PyMol.

unit inserts into the active pocket of the ctEZH2 SET domain, which suggests that $\mathrm{H} 3 \mathrm{~K} 27 \mathrm{M}$ inhibits $c t \mathrm{PRC} 2$ catalysis via the same structural mechanism as for human PRC2 ${ }^{[97]}$.

Although fungal (C thermophilum) PRC2 has a similar overall structure as human PRC2, they have significant differences: first, the fungal EED has three helixes ( $\alpha 1, a 2$ and $\alpha 3$ ) and two $\beta$-sheets ( $\beta 27$ and $\beta 28$ ) from Ile342 to Tyr501 that have unknown function and are not found in human EED. Second, the SBD, SANT1L, SANT2L, CXC and SET domains of fungal EZH2 have different orientations compared to the corresponding domains in human EZH2. As shown biochemically, these structural differences do not affect PRC2 HMTase activity, but they may impact other functions of PRC2 such as RNA binding (Figure 2C).

The flexible SRM of EZH2 is absent in the electron density map of the PRC2 ternary complex in the basal state, suggesting that it is highly flexible in the absence of the stimulating H3K27me3 peptide ${ }^{[93]}$. Comparison between the basal and stimulated states of fungal PRC2 visualizes a dramatic disorder-to-order conformational transition of the SRM upon binding of the H3K27me3 peptide and suggests an allosteric activation model for EZH2 HMTase activity ${ }^{[93,94]}$. According to this model, binding of H3K27me3 or JARID2K116me3 pep- tide induces an interaction with the SRM, through which the SRM becomes structured and binds the catalytic SET-I domain of EZH2. This coupled interaction is associated with a rotation of SET-I and an opening of the substrate-binding cleft, which results in stimulation of PRC2 activity (Figure 4).

The structure of the chimeric human-ac PRC2 in complex with inhibitor is similar to that of fungal PRC2 in the basal state but has several differences relative to active PRC2. The SRM in the absence of the stabilizing H3K27me3 or JARID2K116me3 peptides is not resolved, and inhibitor 1 competitively binds to the co-factor SAH binding site in the pocket of the SET domain, leading to inactivation of EZH2. In addition, the orientations of the SBD and SANT1 subdomains of PRC2 in the inhibitor-bound state differ from active PRC2, although it is not known whether these changes affect PRC2 function (Figure 5).

\section{Drug discovery targeting PRC2}

Given the evidence for oncogenic activity of EZH2 mutations and overexpression, the protein has become an attractive drug target for cancer therapy. Because EZH2 only possesses methytransferase activity when incorporated into PRC2, PRC2 is always used for inhibitor screening. In recent years, a series 

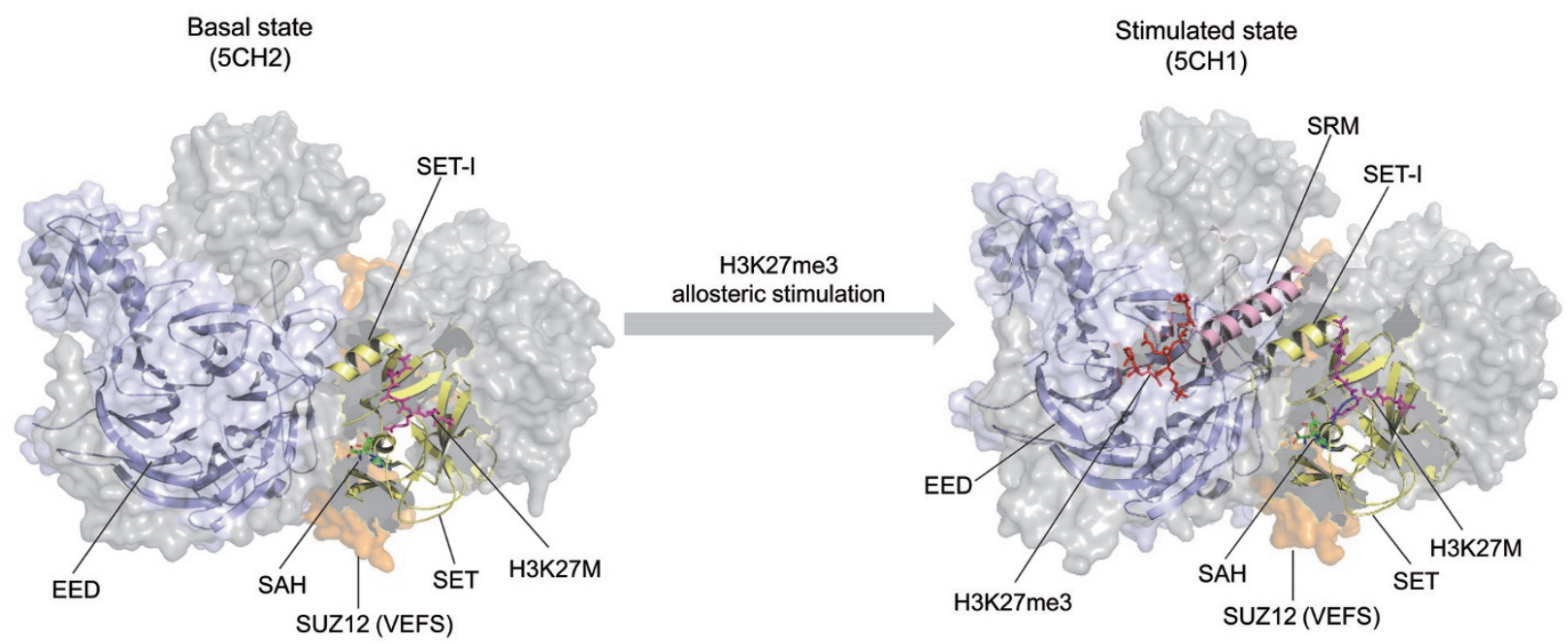

Figure 4. Allosteric regulation of PRC2 activity. The flexible stimulation-responsive motif (SRM) of EZH2 is absent in the electron density map of the PRC2 ternary complex in the basal state ${ }^{[93]}$. The H3K27me3 peptide interaction with the SRM induces SRM structure and allows it to bind the catalytic SET-I domain of EZH2. These coupled interactions are associated with a rotation of SET-I and opening of the substrate-binding cleft, resulting in stimulation of PRC2 activity ${ }^{[93]}$.

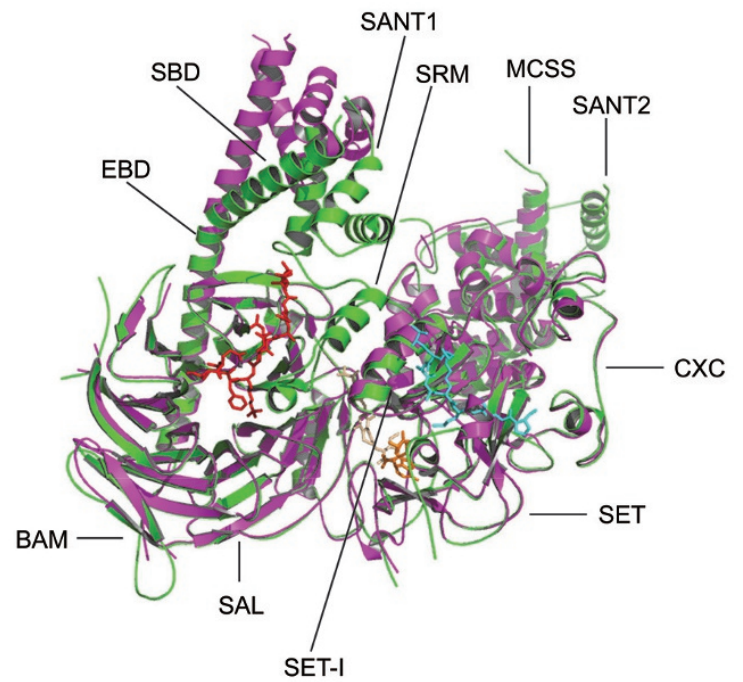

Figure 5. Overlay of the active and inhibitory states of human PRC2. The structure of active (PDB ID: 5HYN) ${ }^{[94]}$ and inhibited PRC2 (PDB ID: 5IJ7) ${ }^{[95]}$. Green: active PRC2, magenta: inhibitory PRC2, red: JARID2K116me2 peptide, cyan: H3K27M peptide, orange: SAH, wheat: Inhibitor 1 from structure $5 \mathrm{IJ} 7$.

of potent inhibitors of PRC2 have been developed. Our group summarized those reported inhibitors in $2014^{[98]}$. Since then, several new inhibitors have been developed (Table 1). Current inhibitors can be classified into three groups.

Non-EZH2-targeted inhibitors: DZNep, a cyclopentanyl analog of 3-deazaadenosine, potently interferes with S-adenosyl-1-homocysteine (SAH) hydrolase, resulting in an increase in cellular SAH levels. SAH is the methyltransfer product of
SAM and a potent product inhibitor of methyltransferases ${ }^{[99]}$. DZNep is therefore not selective for EZH2 but rather also decreases deposition of other histone methylation marks. Treatment with DZNep induces significant antitumor activity in various cancer types ${ }^{[99]}$. SAH can also be isolated from Streptomyces spp cultures as a natural inhibitor. Sinefungin is a PRC2-inhibiting natural SAM and SAH analog ${ }^{[100]}$.

Direct small molecule inhibitors: GSK126, EPZ6438 and UNC1999 are SAM-competitive PRC2 inhibitors that share similar SAM-like scaffolds and have high potency and selectivity ${ }^{[77,101,102]}$. According to a recent study, two novel EZH2 inhibitors, DEC_42 and DEC_254, have been discovered using a combined in silico screening and experimental study ${ }^{[103]}$. This class of inhibitors exhibits a new molecular structure that is different from other EZH2 inhibitors. However, the activities of these two compounds are very low $\left(\mathrm{IC}_{50}\right.$ values of 22.6 $\mu \mathrm{mol} / \mathrm{L}$ and $10.3 \mu \mathrm{mol} / \mathrm{L}$, respectively ${ }^{[103]}$ and require further optimization. JQEZ5 is the most efficacious compound in vitro and exhibits low toxicity and favorable pharmacokinetic properties in vivo, comparable to those of EZH2 inhibitors currently in clinical trials. JQEZ5 demonstrated marked in vivo antitumor activity in a faithful model of EZH2-mutant cancer ${ }^{[78]}$.

Peptide inhibitors: Kim et al designed a stabilized a-helix of EZH2 (SAH-EZH2) peptide based on the EED-EZH2 complex structure. This peptide selectively inhibits H3 Lys27 trimethylation in a dose-dependent response by disrupting the EZH2-EED complex and reducing EZH2 protein levels ${ }^{[104]}$.

The combination of different drugs or methods in cancer therapy can enhance the curative effect and reduce resistance to, and toxicity of, drugs; this strategy has therefore been widely used in cancer therapy. Recently, several groups reported that PRC2/EZH2 inhibition shows strong synergism with other drugs in cancer treatments. Fillmore et al reported 
Table 1. Chemical structures and biochemical data for PRC2 inhibitors.

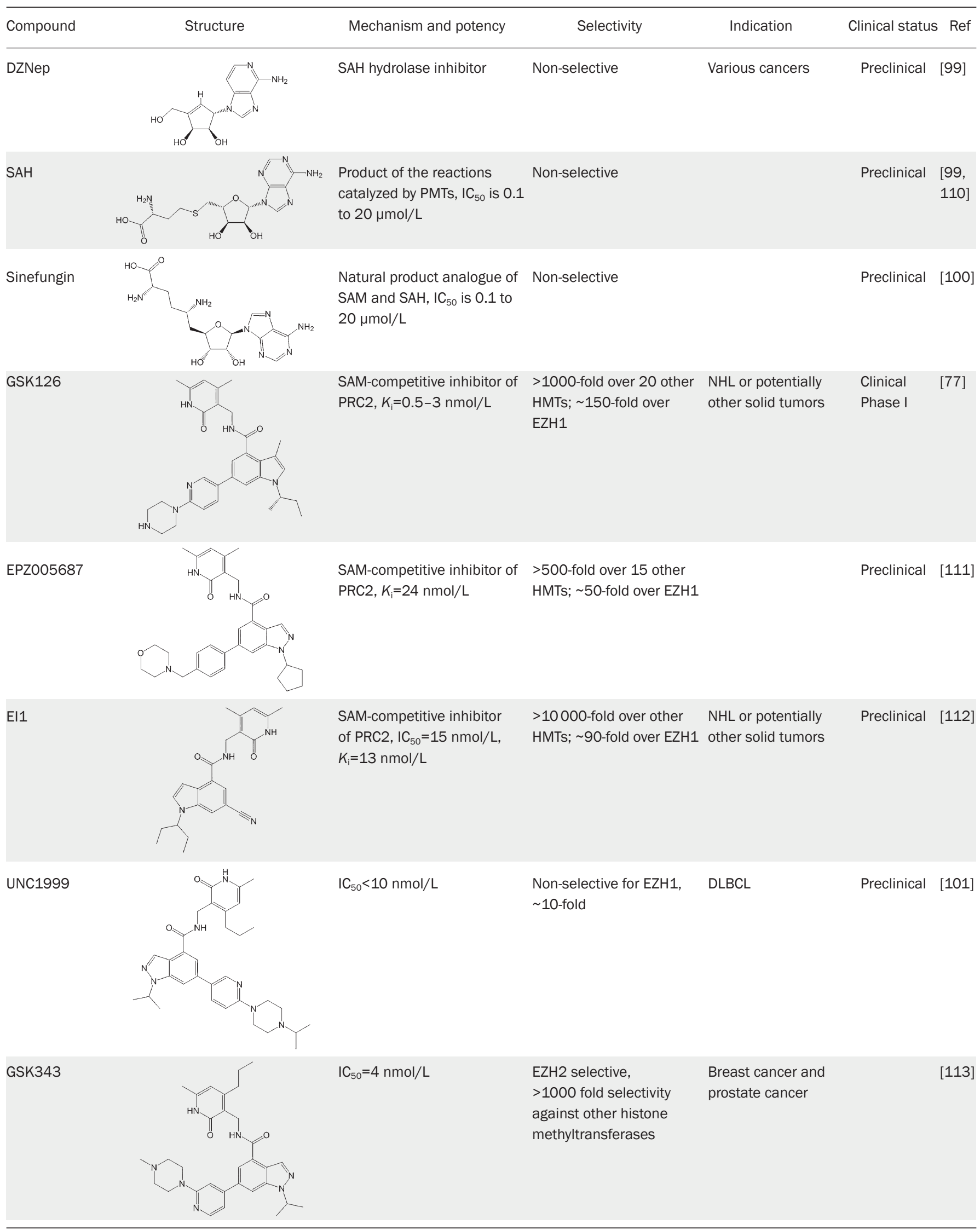




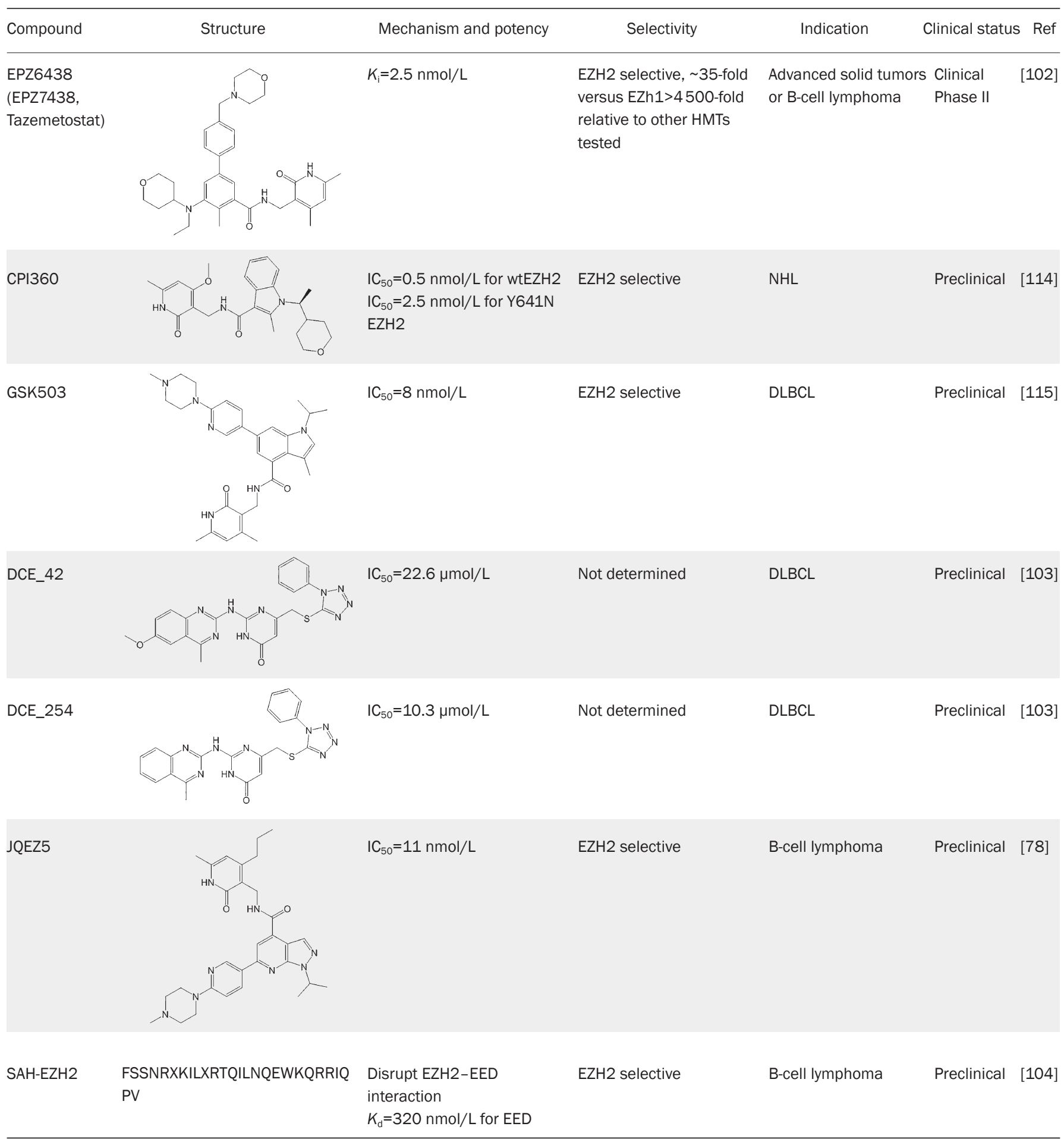

NHL, Non-Hodgkin lymphoma; DLBCL, Diffuse large B-cell lymphoma.

that EZH2 inhibition by DZNep or GSK126 sensitizes BRG1 and EGFR mutant lung tumors to topoisomerase II inhibitors $^{[105]}$. Bitlers et al reported that EZH2 inhibition by GSK126 acts in a synthetic lethal manner in ARID1A-mutated ovarian cancer cells and that ARID1A mutational status correlates with response to the EZH2 inhibitor ${ }^{[81]}$. Souroullaso et al reported an exquisite specific cooperation between activating genetic events of EZH2 and BRAF, which predicts synergistic activity for a combined therapy with RAF inhibitors and EZH2 inhibitors for B cell lymphomas and melanomas that harbor the 
A

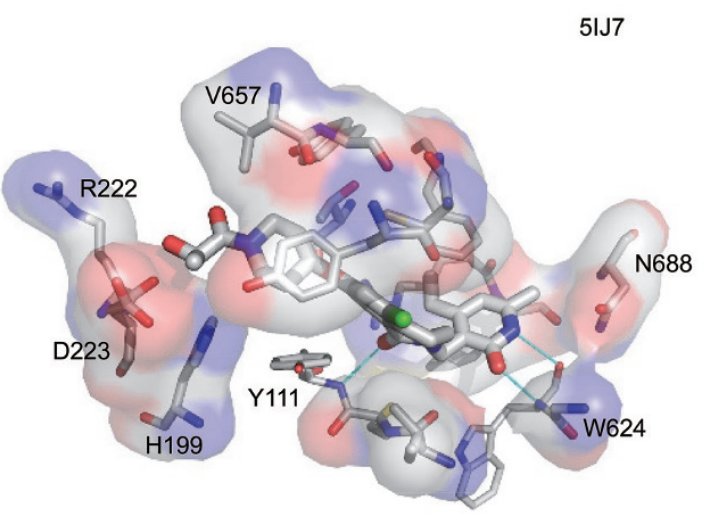

C

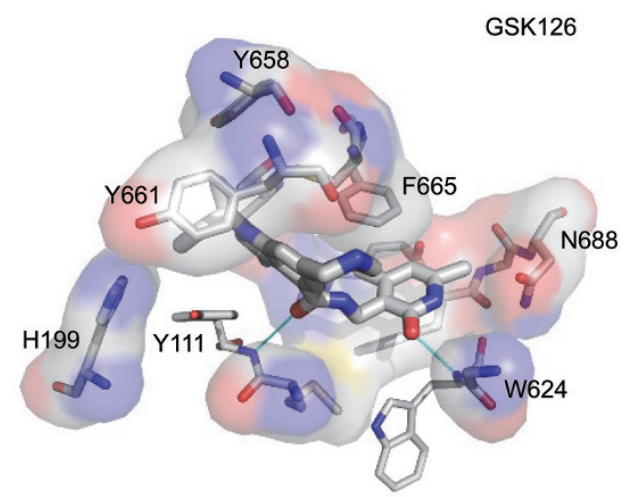

B

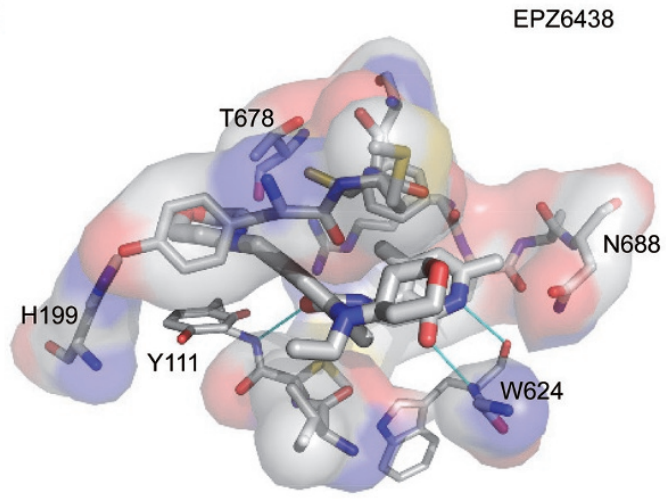

D

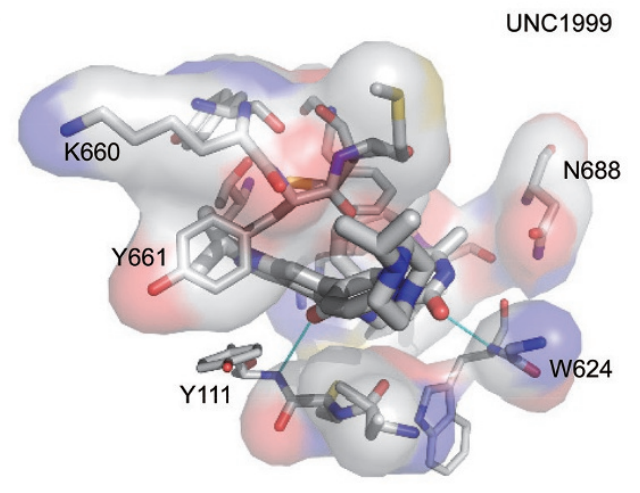

Figure 6. Interaction of PRC2-inhibitor. The program Autodock was used to dock the PRC2 inhibitors EPZ6438, GSK126, and UNC1999 into the crystal structure of the PRC2/Inhibitor 1 complex (PDB code 5IJ7) ${ }^{[95]}$. (A) PRC2-inhibitor 1 interactions. (B) PRC2-EPZ6438 interactions. (C) PRC2-GSK126 interactions. (D) PRC2-UNC1999 interactions.

oncogenic EZH2 Y641F mutation ${ }^{[78]}$. Pharmacological inhibition of EZH2 in combination with other drugs therefore provides a promising novel anti-cancer treatment strategy.

\section{PRC2-inhibitor interaction}

The recently solved structures of PRC2 with the pyridonebased inhibitor 1 or H3K27M substrate peptide provide mechanistic insights into PRC2-inhibitor versus PRC2-substrate binding. EPZ6438, GSK126 and UNC1999 are other pyridonylcontaining SAM-competitive inhibitors that have high affinity and selectivity for EZH2 over a range of unrelated HMTases $\left(K_{\mathrm{d}}\right.$ from $\left.0.1-10 \mathrm{nmol} / \mathrm{L}\right)$. We docked these compounds into the PRC2/Compound 1 structure (5IJ7) to investigate the PRC2-inhibitor binding model.

The pyridonyl group of inhibitor 1 occupies the same position as the homocysteine moiety of SAM and forms two hydrogen bonds with W624 of SUZ12(VEFS). In contrast, the bulk of the inhibitor occupies a unique pocket in which the carbonyl group of its 1-oxo-isoquinoline forms one hydrogen bond with Y111 and the chlorinated aromatic ring exhibits п-п stacking with Y111, Y661 and F665 of the activation loop. In addition, residues Y111, Y661, Y685, C663 and F665 form a hydrophobic channel for compound binding (Figure 6A). PRC2 with EZH2 mutations at Y661 or Y111 is resistant to pyridone inhibitors, consistent with the importance of these two residues for inhibitor binding.

In our docking models, the pyridonyl group of EPZ6438 also forms two hydrogen bonds with W624, while its amide group forms one hydrogen bond with Y111 and the phenyl group undergoes п-п stacking with Y111, Y661 and F665 (Figure 6B). Similarly, docking suggests that the pyridonyl group of GSK126 forms two hydrogen bonds with W624, the amide group one hydrogen bond with Y111 and the indole moiety forms $\Pi-\Pi$ stacking with Y111, Y661 and F665. In addition, the nitrogen of the piperazine moiety may form a hydrogen bond with Y661 (Figure 6C). For UNC1999, in addition to the two hydrogen bonds of the pyridonyl group with W624, the amide group is predicted to form one hydrogen bond with Y111 and the indole moiety to ח-п stack with Y111, Y661 and F665 (Figure 6D).

\section{Future studies}

Although the structure of the EZH2-EED-SUZ12(VEFS) heterotrimer has been determined, a number of key features of PRC2 function, regulation and structure remain to be understood, some of which we have discussed in this review. The understanding of PRC2-specific recruitment to chromatin is far from complete. Recruitment to different chromatin regions is likely mediated by an ensemble of factors, including bridging proteins, DNA elements and RNAs ${ }^{[6,7,59]}, e g,(1)$ the interac- 
tion of the histone chaperones $\operatorname{RbAp} 46 / 48$ with histones ${ }^{[25,106]}$, (2) the interaction of JARID2 and AEBP2 with DNA ${ }^{[27,30,37]},(3)$ recognition of methylated $\mathrm{H} 3 \mathrm{~K} 36$ by the PCL family of proteins ${ }^{[107]}$, and (4) interactions of EZH2 and SUZ12 with transcription factors or noncoding $\operatorname{RNA}^{[22,57-65,71,108,109]}$, which may either act alone or in combination to allow PRC2 targeting to specific genomic loci ${ }^{[1,6]}$.

How do JARID2, AEBP2 and PLCs regulate PRC2 HMTase activity and gene targeting? Are transcription factors essential for initial recruitment, with PRC2 itself being sufficient to maintain gene silencing? What role does the function of noncoding RNAs play in this process? What are the respective functions of H3K27me1, H3K27me2 and H3K27me3, and how are these modifications regulated? The field is still far from having clear answers to these questions ${ }^{[6]}$.

High-resolution structures (Cryo-EM or X-ray) of PRC2 with different regulators or co-factors (JARID2, PCLs, RBFOX2, ncRNAs, etc) will provide critical details regarding these interactions. The structures of PRC2-nucleosome complexes harboring mono-, di-and tri-methylated H3K27 will likely provide clues into the functions of the different methylation states.

Answers to these questions will improve understanding of the function of PRC2 in stem cells and developmental control and of the contribution of PRC2 dysregulation to diseases such as cancer.

Currently, PRC2 inhibitors in clinical trials such as GSK126 and EPZ6438 are PRC2 co-factor SAM-competitive. The structure of the PRC2-inhibitor 1 complex provides high-resolution details of this interaction, which will help design and develop novel chemical scaffolds and molecules with higher selectivity and potency. The existing structures of PRC2 provide information on PRC2-H3K27, PRC2-H3K27me3, EZH2-EED, EZH2SUZ12(VEFS) and EED-SUZ12(VEFS) interactions. In the future, we may develop novel compounds/peptides to disrupt these interactions to suppress PRC2 HMTase activity.

PRC2 is involved in multiple pathways related to cancer, stem cells, and immune responses, modulated by factors such as SWI-SNF, NOTCH/JAK-STAT, pRB, NF-кB/Ras and others $^{[12]}$. PRC2 inhibition may therefore synergize with the drugs targeting these pathways; several studies have already confirmed the effectiveness of combination strategies, some of which we have discussed in this review. In the future, the pharmacological inhibition of PRC2 combined with other drugs or treatments may present novel anticancer therapies.

\section{Acknowledgements}

This work was supported by the Ministry of Science and Technology of China (№ 2012CB910403 and 2013CB910601); the Strategic Priority Research Program of the Chinese Academy of Sciences (No XDB08020303); the Outstanding Young Scientist Foundation, Chinese Academy of Sciences; the Youth Innovation Promotion Association, Chinese Academy of Sciences and the Jay and Betty Van Andel Foundation, Amway (USA).

\section{References}

1 Margueron R, Reinberg D. The Polycomb complex PRC2 and its mark in life. Nature 2011; 469: 343-9.

2 Copeland RA, Olhava EJ, Scott MP. Targeting epigenetic enzymes for drug discovery. Curr Opin Chem Biol 2010; 14: 505-10.

3 Copeland RA, Solomon ME, Richon VM. Protein methyltransferases as a target class for drug discovery. Nat Rev Drug Discov 2009; 8: 724-32.

4 Bauge C, Bazille C, Girard N, Lhuissier E, Boumediene K. Histone methylases as novel drug targets: developing inhibitors of EZH2. Future Med Chem 2014; 6: 1943-65.

5 Greer EL, Shi Y. Histone methylation: a dynamic mark in health, disease and inheritance. Nat Rev Genet 2012; 13: 343-57.

6 Di Croce L, Helin K. Transcriptional regulation by Polycomb group proteins. Nat Struct Mol Biol 2013; 20: 1147-55.

7 Simon JA, Kingston RE. Occupying chromatin: Polycomb mechanisms for getting to genomic targets, stopping transcriptional traffic, and staying put. Mol Cell 2013; 49: 808-24.

8 McGinty RK, Henrici RC, Tan S. Crystal structure of the PRC1 ubiquitylation module bound to the nucleosome. Nature 2014; 514: 591-6.

9 Laugesen A, Hojfeldt JW, Helin K. Role of the polycomb repressive complex 2 (PRC2) in transcriptional regulation and cancer. Cold Spring Harb Perspect Med 2016; 6.

10 Cavalli G. Molecular biology. EZH2 goes solo. Science 2012; 338: 1430-1.

11 Chang $\mathrm{CJ}$, Hung MC. The role of EZH2 in tumour progression. $\mathrm{Br} J$ Cancer 2012; 106: 243-7.

12 Kim KH, Roberts CW. Targeting EZH2 in cancer. Nat Med 2016; 22 : 128-34.

13 Margueron R, Justin N, Ohno K, Sharpe ML, Son J, Drury WJ 3rd, et al. Role of the polycomb protein EED in the propagation of repressive histone marks. Nature 2009; 461: 762-7.

14 Cao R, Zhang Y. SUZ12 is required for both the histone methyltransferase activity and the silencing function of the EED-EZH2 complex. Mol Cell 2004; 15: 57-67.

15 Montgomery ND, Yee D, Montgomery SA, Magnuson T. Molecular and functional mapping of EED motifs required for PRC2-dependent histone methylation. J Mol Biol 2007; 374: 1145-57.

16 Han Z, Xing X, Hu M, Zhang Y, Liu P, Chai J. Structural basis of EZH2 recognition by EED. Structure 2007; 15: 1306-15.

17 Pasini D, Bracken AP, Jensen MR, Lazzerini Denchi E, Helin K. Suz12 is essential for mouse development and for EZH2 histone methyltransferase activity. EMBO J 2004; 23: 4061-71.

18 O'Meara MM, Simon JA. Inner workings and regulatory inputs that control Polycomb repressive complex 2. Chromosoma 2012; 121 : 221-34.

19 Ketel CS, Andersen EF, Vargas ML, Suh J, Strome S, Simon JA. Subunit contributions to histone methyltransferase activities of fly and worm polycomb group complexes. Mol Cell Biol 2005; 25: 6857-68.

20 Schmitges FW, Prusty AB, Faty M, Stutzer A, Lingaraju GM, Aiwazian $\mathrm{J}$, et al. Histone methylation by PRC2 is inhibited by active chromatin marks. Mol Cell 2011; 42: 330-41.

21 Peng JC, Valouev A, Swigut T, Zhang J, Zhao Y, Sidow A, et al. Jarid2/ Jumonji coordinates control of PRC2 enzymatic activity and target gene occupancy in pluripotent cells. Cell 2009; 139: 1290-302.

22 Kanhere A, Viiri K, Araujo CC, Rasaiyaah J, Bouwman RD, Whyte WA, et al. Short RNAs are transcribed from repressed polycomb target genes and interact with polycomb repressive complex-2. Mol Cell 2010; 38: 675-88.

23 Alqarni SS, Murthy A, Zhang W, Przewloka MR, Silva AP, Watson AA, et al. Insight into the architecture of the NuRD complex: structure of the RbAp48-MTA1 subcomplex. J Biol Chem 2014; 289: 21844-55. 
24 Lejon S, Thong SY, Murthy A, AIQarni S, Murzina NV, Blobel GA, et al. Insights into association of the NuRD complex with FOG-1 from the crystal structure of an RbAp48.FOG-1 complex. J Biol Chem 2011; 286: 1196-203.

25 Murzina NV, Pei XY, Zhang W, Sparkes M, Vicente-Garcia J, Pratap $\mathrm{JV}$, et al. Structural basis for the recognition of histone $\mathrm{H} 4$ by the histone-chaperone RbAp46. Structure 2008; 16: 1077-85.

26 Nekrasov M, Wild B, Muller J. Nucleosome binding and histone methyltransferase activity of Drosophila PRC2. EMBO Rep 2005; 6: 348-53.

27 Kim H, Kang K, Kim J. AEBP2 as a potential targeting protein for Polycomb Repression Complex PRC2. Nucleic Acids Res 2009; 37: 2940-50.

28 Ciferri C, Lander GC, Maiolica A, Herzog F, Aebersold R, Nogales E. Molecular architecture of human polycomb repressive complex 2 . eLife 2012; 1: e00005.

29 Kim TG, Kraus JC, Chen J, Lee Y. JUMONJI, a critical factor for cardiac development, functions as a transcriptional repressor. J Biol Chem 2003; 278: 42247-55.

30 Pasini D, Cloos PA, Walfridsson J, Olsson L, Bukowski JP, Johansen JV, et al. JARID2 regulates binding of the Polycomb repressive complex 2 to target genes in ES cells. Nature 2010; 464: 306-10.

31 Son J, Shen SS, Margueron R, Reinberg D. Nucleosome-binding activities within JARID2 and EZH1 regulate the function of PRC2 on chromatin. Genes Develop 2013; 27: 2663-77.

32 Sanulli S, Justin N, Teissandier A, Ancelin K, Portoso M, Caron M, et al. Jarid2 methylation via the PRC2 complex regulates H3K27me3 deposition during cell differentiation. Mol Cell 2015; 57: 769-83.

33 Kaneko S, Bonasio R, Saldana-Meyer R, Yoshida T, Son J, Nishino K, et al. Interactions between JARID2 and noncoding RNAs regulate PRC2 recruitment to chromatin. Mol Cell 2014; 53: 290-300.

34 da Rocha ST, Boeva V, Escamilla-Del-Arenal M, Ancelin K, Granier C, Matias NR, et al. Jarid2 is implicated in the initial Xist-induced targeting of PRC2 to the inactive X chromosome. Mol Cell 2014; 53 : 301-16.

35 Mysliwiec MR, Carlson CD, Tietjen J, Hung H, Ansari AZ, Lee Y. Jarid2 (Jumonji, AT rich interactive domain 2) regulates NOTCH1 expression via histone modification in the developing heart. J Biol Chem 2012; 287: 1235-41.

36 Zhang Z, Jones A, Sun CW, Li C, Chang CW, Joo HY, et al. PRC2 complexes with JARID2, MTF2, and esPRC2p48 in ES cells to modulate ES cell pluripotency and somatic cell reprogramming. Stem Cells 2011; 29: 229-40.

37 Li G, Margueron R, Ku M, Chambon P, Bernstein BE, Reinberg D. Jarid2 and PRC2, partners in regulating gene expression. Genes Develop 2010; 24: 368-80.

38 Landeira D, Sauer S, Poot R, Dvorkina M, Mazzarella L, Jorgensen HF, et al. Jarid2 is a PRC2 component in embryonic stem cells required for multi-lineage differentiation and recruitment of PRC1 and RNA polymerase II to developmental regulators. Nat Cell Biol 2010; 12: 618-24.

39 Herz HM, Shilatifard A. The JARID2-PRC2 duality. Genes Develop 2010; 24: 857-61.

40 Shen X, Kim W, Fujiwara Y, Simon MD, Liu Y, Mysliwiec MR, et al. Jumonji modulates polycomb activity and self-renewal versus differentiation of stem cells. Cell 2009; 139: 1303-14.

41 Duncan IM. Polycomblike: a gene that appears to be required for the normal expression of the bithorax and antennapedia gene complexes of Drosophila melanogaster. Genetics 1982; 102: 49-70.

42 Inouye C, Remondelli P, Karin M, Elledge S. Isolation of a cDNA encoding a metal response element binding protein using a novel expression cloning procedure: the one hybrid system. DNA Cell Biol 1994; 13: 731-42.

43 Coulson M, Robert S, Eyre HJ, Saint R. The identification and localization of a human gene with sequence similarity to polycomblike of Drosophila melanogaster. Genomics 1998; 48: 381-3.

44 Wang S, Robertson GP, Zhu J. A novel human homologue of Drosophila polycomblike gene is up-regulated in multiple cancers. Gene 2004; 343: 69-78.

45 Sarma K, Margueron R, Ivanov A, Pirrotta V, Reinberg D. Ezh2 requires PHF1 to efficiently catalyze H3 lysine 27 trimethylation in vivo. Mol Cell Biol 2008; 28: 2718-31.

46 Cao R, Wang H, He J, Erdjument-Bromage H, Tempst P, Zhang Y. Role of hPHF1 in H3K27 methylation and Hox gene silencing. Mol Cell Biol 2008; 28: 1862-72.

47 Hong Z, Jiang J, Lan L, Nakajima S, Kanno S, Koseki H, et al. A polycomb group protein, PHF1, is involved in the response to DNA doublestrand breaks in human cell. Nucleic Acids Res 2008; 36: 2939-47.

48 Yang $\mathrm{Y}$, Wang $\mathrm{C}$, Zhang $\mathrm{P}$, Gao K, Wang D, Yu H, et al. Polycomb group protein PHF1 regulates $p 53-d e p e n d e n t$ cell growth arrest and apoptosis. J Biol Chem 2013; 288: 529-39.

49 Li X, Isono K, Yamada D, Endo TA, Endoh M, Shinga J, et al. Mammalian polycomb-like Pcl2/Mtf2 is a novel regulatory component of PRC2 that can differentially modulate polycomb activity both at the Hox gene cluster and at Cdkn2a genes. Mol Cell Biol 2011; 31: 351-64.

50 Walker E, Chang WY, Hunkapiller J, Cagney G, Garcha K, Torchia J, et al. Polycomb-like 2 associates with PRC2 and regulates transcriptional networks during mouse embryonic stem cell self-renewal and differentiation. Cell Stem Cell 2010; 6: 153-66.

51 Boulay G, Rosnoblet C, Guerardel C, Angrand PO, Leprince D. Functional characterization of human Polycomb-like 3 isoforms identifies them as components of distinct EZH2 protein complexes. Biochem J 2011; 434: 333-42.

52 Hunkapiller J, Shen Y, Diaz A, Cagney G, McCleary D, Ramalho-Santos $\mathrm{M}$, et al. Polycomb-like 3 promotes polycomb repressive complex 2 binding to $\mathrm{CpG}$ islands and embryonic stem cell self-renewal. PLoS Genet 2012; 8: e1002576.

53 Ballare C, Lange M, Lapinaite A, Martin GM, Morey L, Pascual G, et al. Phf19 links methylated Lys36 of histone $\mathrm{H} 3$ to regulation of Polycomb activity. Nat Struct Mol Biol 2012; 19: 1257-65.

54 Brien GL, Gambero G, O'Connell DJ, Jerman E, Turner SA, Egan $\mathrm{CM}$, et al. Polycomb PHF19 binds H3K36me3 and recruits PRC2 and demethylase N066 to embryonic stem cell genes during differentiation. Nat Struct Mol Biol 2012; 19: 1273-81.

55 Musselman CA, Avvakumov N, Watanabe R, Abraham CG, Lalonde $\mathrm{ME}$, Hong Z, et al. Molecular basis for $\mathrm{H} 3 \mathrm{~K} 36 \mathrm{me} 3$ recognition by the Tudor domain of PHF1. Nat Struct Mol Biol 2012; 19: 1266-72.

56 Farcas AM, Blackledge NP, Sudbery I, Long HK, McGouran JF, Rose NR, et al. KDM2B links the Polycomb Repressive Complex 1 (PRC1) to recognition of CpG islands. eLife 2012; 1: e00205.

57 Liu GY, Zhao GN, Chen XF, Hao DL, Zhao X, Lv X, et al. The long noncoding RNA Gm15055 represses Hoxa gene expression by recruiting PRC2 to the gene cluster. Nucleic Acids Res 2016; 44: 2613-27.

58 Liu C, Li S, Dai X, Ma J, Wan J, Jiang H, et al. PRC2 regulates RNA polymerase III transcribed non-translated RNA gene transcription through EZH2 and SUZ12 interaction with TFIIIC complex. Nucleic Acids Res 2015; 43: 6270-84.

59 Davidovich C, Wang X, Cifuentes-Rojas C, Goodrich KJ, Gooding AR, Lee JT, et al. Toward a consensus on the binding specificity and promiscuity of PRC2 for RNA. Mol Cell 2015; 57: 552-8. 
60 Sarma K, Cifuentes-Rojas C, Ergun A, Del Rosario A, Jeon Y, White $\mathrm{F}$, et al. ATRX directs binding of PRC2 to Xist RNA and Polycomb targets. Cell 2014; 159: 869-83.

61 Kretz M, Meister G. RNA binding of PRC2: promiscuous or well ordered? Mol Cell 2014; 55: 157-8.

62 Cifuentes-Rojas C, Hernandez AJ, Sarma K, Lee JT. Regulatory interactions between RNA and polycomb repressive complex 2. Mol Cell 2014; 55: 171-85.

63 Wu L, Murat P, Matak-Vinkovic D, Murrell A, Balasubramanian S. Binding interactions between long noncoding RNA HOTAIR and PRC2 proteins. Biochemistry 2013; 52: 9519-27.

64 Kaneko S, Son J, Shen SS, Reinberg D, Bonasio R. PRC2 binds active promoters and contacts nascent RNAs in embryonic stem cells. Nat Struct Mol Biol 2013; 20: 1258-64.

65 Davidovich C, Zheng L, Goodrich KJ, Cech TR. Promiscuous RNA binding by Polycomb repressive complex 2. Nat Struct Mol Biol 2013; 20: 1250-7.

66 Kaneko S, Li G, Son J, Xu CF, Margueron R, Neubert TA, et al. Phosphorylation of the PRC2 component Ezh2 is cell cycle-regulated and up-regulates its binding to ncRNA. Genes Develop 2010; 24: 2615-20.

67 Davidovich C, Cech TR. The recruitment of chromatin modifiers by long noncoding RNAs: lessons from PRC2. RNA 2015; 21: 2007-22.

68 Rinn JL, Kertesz M, Wang JK, Squazzo SL, Xu X, Brugmann SA, et al. Functional demarcation of active and silent chromatin domains in human HOX loci by noncoding RNAs. Cell 2007; 129: 1311-23.

69 Pandey RR, Mondal T, Mohammad F, Enroth S, Redrup L, Komorowski $\mathrm{J}$, et al. Kcnq1ot1 antisense noncoding RNA mediates lineagespecific transcriptional silencing through chromatin-level regulation. Mol Cell 2008; 32: 232-46.

70 Zhao J, Ohsumi TK, Kung JT, Ogawa Y, Grau DJ, Sarma K, et al. Genome-wide identification of polycomb-associated RNAs by RIP-seq. Mol Cell 2010; 40: 939-53.

71 Wei C, Xiao R, Chen L, Cui H, Zhou Y, Xue Y, et al. RBFox2 binds nascent RNA to globally regulate polycomb complex 2 targeting in mammalian genomes. Mol Cell 2016; 62: 875-89.

72 Wassef M, Margueron R. The multiple facets of PRC2 alterations in cancers. J Mol Biol 2016. pii: S0022-2836(16)30427-2. doi: 10.1016/j.jmb.2016.10.012.

73 Conway E, Healy E, Bracken AP. PRC2 mediated H3K27 methylations in cellular identity and cancer. Curr Opin Cell Biol 2015; 37: 42-8.

74 Lee TI, Jenner RG, Boyer LA, Guenther MG, Levine SS, Kumar RM, et al. Control of developmental regulators by Polycomb in human embryonic stem cells. Cell 2006; 125: 301-13.

75 von Schimmelmann M, Feinberg PA, Sullivan JM, Ku SM, Badimon A, Duff MK, et al. Polycomb repressive complex 2 (PRC2) silences genes responsible for neurodegeneration. Nat Neurosci 2016; 19: 1321-30.

$76 \mathrm{Xu} \mathrm{B}$, Konze KD, Jin J, Wang GG. Targeting EZH2 and PRC2 dependence as novel anticancer therapy. Exp Hematol 2015; 43: 698-712.

77 McCabe MT, Ott HM, Ganji G, Korenchuk S, Thompson C, Van Aller GS, et al. EZH2 inhibition as a therapeutic strategy for lymphoma with EZH2-activating mutations. Nature 2012; 492: 108-12.

78 Souroullas GP, Jeck WR, Parker JS, Simon JM, Liu JY, Paulk J, et al. An oncogenic Ezh2 mutation induces tumors through global redistribution of histone 3 lysine 27 trimethylation. Nat Med 2016; 22: 632-40.

79 Hernando H, Gelato KA, Lesche R, Beckmann G, Koehr S, Otto S, et al. EZH2 inhibition blocks multiple myeloma cell growth through upregulation of epithelial tumor suppressor genes. Mol Cancer Ther
2016; 15: 287-98.

80 Vizan P, Beringer M, Ballare C, Di Croce L. Role of PRC2-associated factors in stem cells and disease. FEBS J 2015; 282: 1723-35.

81 Bitler BG, Aird KM, Garipov A, Li H, Amatangelo M, Kossenkov AV, et al. Synthetic lethality by targeting EZH2 methyltransferase activity in ARID1A-mutated cancers. Nat Med 2015; 21: 231-8.

82 Li LY. EZH2: novel therapeutic target for human cancer. BioMedicine 2014; 4: 1.

83 Kondo Y. Targeting histone methyltransferase EZH2 as cancer treatment. J Biochem 2014; 156: 249-57.

84 Knutson SK, Kawano S, Minoshima Y, Warholic NM, Huang KC, Xiao $\mathrm{Y}$, et al. Selective inhibition of EZH2 by EPZ-6438 leads to potent antitumor activity in EZH2-mutant non-Hodgkin lymphoma. Mol Cancer Ther 2014; 13: 842-54.

85 Crea F, Paolicchi E, Marquez VE, Danesi R. Polycomb genes and cancer: time for clinical application? Crit Rev Oncol Hematol 2012; 83: 184-93.

86 Crea F, Fornaro L, Bocci G, Sun L, Farrar WL, Falcone A, et al. EZH2 inhibition: targeting the crossroad of tumor invasion and angiogenesis. Cancer Metastasis Rev 2012; 31: 753-61.

87 Richly H, Aloia L, Di Croce L. Roles of the Polycomb group proteins in stem cells and cancer. Cell Death Disease 2011; 2: e204.

88 Chase A, Cross NC. Aberrations of EZH2 in cancer. Clin Cancer Res 2011; 17: 2613-8.

89 Giulino-Roth L. EZH2: a potential new target in T-cell lymphoma? Leukemia Lymphoma 2015; 56: 1924-5.

90 Gunawan M, Venkatesan N, Loh JT, Wong JF, Berger H, Neo WH, et al. The methyltransferase Ezh2 controls cell adhesion and migration through direct methylation of the extranuclear regulatory protein talin. Nat Immunol 2015; 16: 505-16.

91 Bantug GR, Hess C. Glycolysis and EZH2 boost T cell weaponry against tumors. Nat Immunol 2016; 17: 41-2.

92 Zhao E, Maj T, Kryczek I, Li W, Wu K, Zhao L, et al. Cancer mediates effector T cell dysfunction by targeting microRNAs and EZH2 via glycolysis restriction. Nat Immunol 2016; 17: 95-103.

93 Jiao L, Liu X. Structural basis of histone H3K27 trimethylation by an active polycomb repressive complex 2 . Science 2015; 350: aac4383.

94 Justin N, Zhang Y, Tarricone C, Martin SR, Chen S, Underwood E, et al. Structural basis of oncogenic histone H3K27M inhibition of human polycomb repressive complex 2. Nat Commun 2016; 7 : 11316.

95 Brooun A, Gajiwala KS, Deng YL, Liu W, Bolanos B, Bingham P, et al. Polycomb repressive complex 2 structure with inhibitor reveals a mechanism of activation and drug resistance. Nat Commun 2016; 7: 11384.

96 Zhang Y, Justin N, Wilson JR, Gamblin SJ. Comment on "Structural basis of histone H3K27 trimethylation by an active polycomb repressive complex 2". Science 2016; 354: 1543.

97 Jiao L, Liu X. Response to comment on "structural basis of histone H3K27 trimethylation by an active polycomb repressive complex 2". Science 2016; 354: 1543.

98 Tan JZ, Yan Y, Wang XX, Jiang Y, Xu HE. EZH2: biology, disease, and structure-based drug discovery. Acta Pharmacol Sin 2014; 35: 16174.

99 Tan J, Yang X, Zhuang L, Jiang X, Chen W, Lee PL, et al. Pharmacologic disruption of polycomb-repressive complex 2-mediated gene repression selectively induces apoptosis in cancer cells. Genes Develop 2007; 21: 1050-63.

100 Couture JF, Hauk G, Thompson MJ, Blackburn GM, Trievel RC. Catalytic roles for carbon-oxygen hydrogen bonding in SET domain 
lysine methyltransferases. J Biol Chem 2006; 281: 19280-7.

101 Konze KD, Ma A, Li F, Barsyte-Lovejoy D, Parton T, Macnevin CJ, et al. An orally bioavailable chemical probe of the lysine methyltransferases EZH2 and EZH1. ACS Chem Biol 2013; 8: 1324-34.

102 Knutson SK, Warholic NM, Wigle TJ, Klaus CR, Allain CJ, Raimondi $\mathrm{A}$, et al. Durable tumor regression in genetically altered malignant rhabdoid tumors by inhibition of methyltransferase EZH2. Proc Natl Acad Sci U S A 2013; 110: 7922-7.

103 Wu Y, Hu J, Ding H, Chen L, Zhang Y, Liu R, et al. Identification of novel EZH2 inhibitors through pharmacophore-based virtual screening and biological assays. Bioorg Med Chem Lett 2016; 26 : 3813-7.

104 Kim W, Bird GH, Neff T, Guo G, Kerenyi MA, Walensky LD, et al. Targeted disruption of the EZH2-EED complex inhibits EZH2dependent cancer. Nat Chem Biol 2013; 9: 643-50.

105 Fillmore CM, Xu C, Desai PT, Berry JM, Rowbotham SP, Lin YJ, et al. EZH2 inhibition sensitizes BRG1 and EGFR mutant lung tumours to Topoll inhibitors. Nature 2015; 520: 239-42.

106 Zhang W, Tyl M, Ward R, Sobott F, Maman J, Murthy AS, et al. Structural plasticity of histones $\mathrm{H} 3-\mathrm{H} 4$ facilitates their allosteric exchange between RbAp48 and ASF1. Nat Struct Mol Biol 2013; 20 : 29-35.

107 Nekrasov M, Klymenko T, Fraterman S, Papp B, Oktaba K, Kocher T, et al. Pcl-PRC2 is needed to generate high levels of H3-K27 trimethylation at Polycomb target genes. EMBO J 2007; 26: 4078-88.
108 Betancur JG, Tomari Y. Cryptic RNA-binding by PRC2 components EZH2 and SUZ12. RNA Biol 2015; 12: 959-65.

109 Kaneko S, Son J, Bonasio R, Shen SS, Reinberg D. Nascent RNA interaction keeps PRC2 activity poised and in check. Genes Develop 2014; 28: 1983-8.

110 Chiang PK. Biological effects of inhibitors of S-adenosylhomocysteine hydrolase. Pharmacol Ther 1998; 77: 115-34.

111 Knutson SK, Wigle TJ, Warholic NM, Sneeringer CJ, Allain CJ, Klaus $\mathrm{CR}$, et al. A selective inhibitor of EZH2 blocks H3K27 methylation and kills mutant lymphoma cells. Nat Chem Biol 2012; 8: 890-6.

112 Qi W, Chan H, Teng L, Li L, Chuai S, Zhang R, et al. Selective inhibition of Ezh2 by a small molecule inhibitor blocks tumor cells proliferation. Proc Natl Acad Sci U S A 2012; 109: 21360-5.

113 Amatangelo MD, Garipov A, Li H, Conejo-Garcia JR, Speicher DW, Zhang R. Three-dimensional culture sensitizes epithelial ovarian cancer cells to EZH2 methyltransferase inhibition. Cell Cycle 2013; 12: 2113-9.

114 Bruno NC, Tudge MT, Buchwald SL. Design and preparation of new palladium precatalysts for $\mathrm{C}-\mathrm{C}$ and $\mathrm{C}-\mathrm{N}$ cross-coupling reactions. Chem Sci 2013; 4: 916-20.

115 Zingg D, Debbache J, Schaefer SM, Tuncer E, Frommel SC, Cheng P, et al. The epigenetic modifier EZH2 controls melanoma growth and metastasis through silencing of distinct tumour suppressors. Nat Commun 2015; 6: 6051. 